\title{
EMPOWERING VOICES OF ENTREPRENEURIAL/ENTERPRISE LEADERSHIP FROM WITHIN: A LEARNING JOURNEY
}

\author{
Sandy Geyer and Jan Hendrik Roodt
}

\begin{abstract}
WARM UP
The thesis presented for investigation in this paper is that entrepreneurial and enterprise leaders of the future may be better served with early-life self-awareness interventions than by current leadership training initiatives. No assumption is held by the authors that everyone exposed to such an intervention might be headed towards a future entrepreneurial/enterprise leadership role. However, practitioner experiences suggest that self-awareness learning can be relevant to all students as a foundation for effective self-leadership through high school, diverse future career choices and in being positive influencers of others. The voices of successful practitioners are arranged alongside the proto-voices of young personas. The insights gathered through surveys and interviews are considered and the first iteration of a 'Leadership Literacy for Life' course is developed, ready for trial in New Zealand and South Africa from June 2021. Future work will use the outcomes from the trial to modify and refine the intervention for the next stage of delivery.
\end{abstract}

\section{OVERTURE}

The question that this research sets out to explore begins with the solo voice of the professional practitioner and asks "How can we better prepare our future entrepreneurial/enterprise leaders earlier in their education?"

I am an entrepreneurial leader. I was also a student leader. In my professional practice, I work daily with entrepreneurial leaders and student leaders in both New Zealand and South Africa. Through this dual-lens, I have become aware of a fundamental void between the two environments of leadership that my question seeks to illuminate. As I draw on my own experience, I am conscious that my writing is auto-ethnographic in orientation. I recognise that my solo call lacks a broader range of harmonies, with the perspective and experience of other educated and cooperative voices appropriate to the nature of the transdisciplinary enquiry, stimulated by this question. And so, "I" becomes "we" as this journey of learning begins with the insightful undertones of my research supervisors. Through deep discussion, we co-construct an appropriate learning agreement to encompass as many voices as we can to seek an educated and practical answer towards earlier empowerment of our future leaders. Our plan through the flow of the research path is to explore the conduits of our future leaders, from birth, through the traditional school structure towards an entrepreneurial/enterprise environment in which there is currently a very high failure rate in both New Zealand and South Africa (Bushe, 2019; Mansfield, 2019).

The entrepreneurial environment presents, from practitioner experience, as one which requires a strong sense of individuality (Geyer, 2013) and creativity that the traditional school structure has not been designed to encourage or facilitate (TED, 2007). This traditional structure, as an environment of nurturing for such skills, was questioned early and rigorously by American philosopher John Dewey. Dewey described it in the early twentieth century as reflective of "traditional patterns of organisation" where "the attitude of the students must be, upon the whole, one of docility, receptivity, and obedience" (Dewey, 1997, p. 28) 
Through the development of the research strategy, three other voices in the form of student personas join Dewey's voice in the lived experience of the school structure as it remains in their reality today. A reality that requires silence in disagreement or at the most mimicking in agreement. To break their silence, the personas speak through the voice of the practitioner to narrate their first experiences of leadership within a hierarchical school structure, where the concept of leadership is mostly disclosed as transactional (Archard, 20 I2; Coffey \& Lavery, 20 8; Hine, 2014; McNae, 20 II). Jordan expresses his uncertainty about his fit to the transactional model which requires of him certain traits to uphold its hierarchical structure. He describes an uncomfortable tension between what his school structure demands of him and what his friends truly know him to be. He wonders if simply enforcing rules which he did not have any say in is really leadership. Tom openly expresses his disdain for the student leadership role towards which he has been assigned, purely as the last family member to pass through a long line of previous school leaders. He recognises the lack of any valuable learning longevity from this role designed for those not at all like himself, and he withdraws in quiet contempt. Tiffany, in her desire to please and gain recognition, embraces the role which deposits her at the beginning of her college experience with no sense of her authentic self with which to make the transition into a less structured environment, with fewer rules. Their voices, whilst uniquely different, join ours in a call to bridge the gap between their experience of student leadership, tightly bound in traditional hierarchical expectation, and the demands of a possible future enterprise/ entrepreneurial leadership role, which presents itself with no traditional boundaries whatsoever.

\section{SETTING THE STAGE - RESEARCH STRATEGY AND METHODS}

The research supervisory team turns from explorative discussion to deeper debate in consideration of an appropriate research design. A set of methodologies is considered including grounded theory, pragmatic qualitative methodology, and constructivism to expand our lens of enquiry and interpretation as we prepare to engage in the first cycle of an action research approach. With its dual aim of addressing real-world problems and improving professional practice by means of combining scholarly observations with practical interventions, we deliberate the five principles of canonical action research (Davison et al., 2004). The fourth principle of ensuring that the research is appropriately actioned to improve the client's problematic situation presents some challenges, with regards to the pragmatic assumption of the presence of a clear client, as we cross disciplines to collect our contributing voices (livari \& Venable, 2009). Who will our collective voices of enquiry be calling to?

\section{INTERLUDE - BRIEF LITERATURE CONTEXT}

If we are to build a bridge over the fundamental void that our question illuminates, we feel it is more constructive to clarify the endpoint and look first to where we are calling 'from.' The path of enquiry thus begins with the exploration of existing scholarly voices to help us understand how they have experienced, understood, and explained concepts of entrepreneurship and entrepreneurial leadership. Within the guiding framework of our research question, however, we hear only what can best be described as echoes from past academic enquiry within the vast, unstructured, and largely misunderstood spaces of entrepreneurship. The explorations included in our review appear to assume that successful entrepreneurship happens by means of an outside-in process. The notion of successful entrepreneurship is hence explored with attention to the effectiveness and replicability of systems, processes, and methods (Moroz \& Hindle, 2012). Entrepreneurial teaching methods, explored as possible ways to prepare for the diverse nature of the demands of the entrepreneurial environment too, point their focus of enquiry to processes, models, and systems to present an academically proven approach for future entrepreneurs (Neck \& Corbett, 2018; Nieuwenhuizen et al., 2016). Studies that do consider the possibility that successful entrepreneurship may be an inside-out process, seek to pursue common traits to explain success or failure with the idea that one is or is not born with entrepreneurial traits (Caliendo et al., 20ll; Kolb \& Wagner, 2015). An opposing voice points out that there seem to be more trait differences within a group of entrepreneurs than between entrepreneurs and non-entrepreneurs (Gartner, 1985). 
The continued call from researchers in the field of entrepreneurship for future research to uncover a proven process strikes a disharmony in the choir of voices we seek, and underestimates the impact of each entrepreneur as a unique individual and the nature of successful entrepreneurship as a wicked problem in a dynamic crossdisciplinary field (Crowley \& Head, 2017; Neck \& Greene, 2011; Rittel \& Webber, 1973). Entrepreneurial leadership, it is agreed though, is a relatively new concept, differing from other more traditional styles of leadership such as transactional, authoritative, and transformational leadership, and it deserves stand-alone attention as a unique form of leadership (Chung-Wen, 2008; Johnson et al., 1998). Practitioner experience in working with many entrepreneurial leaders, across diverse business sizes and industries, suggests that entrepreneurial leadership is an overarching umbrella form of leadership that encompasses many different styles of leadership to suit different circumstances and industry dynamics.

Following the literature review, our next phase of research calls for more practically experienced voices to address the nature of successful entrepreneurial leadership directly from a purposeful sample selection from the field. We choose a mixed-methods approach that seeks the combined voices of currently successful entrepreneurs in both New Zealand and South Africa by means of a wider sample from an online anonymous survey and a smaller sample of one-on-one interviews. COVID-19 acts as an unintentional context to the understood definition of 'currently successful' which requires participants to have successfully navigated the challenges of the COVID-19 pandemic, so far.

\section{THE CHOIR - SURVEY RESULTS}

Two hundred and sixteen anonymous voices speak to us through the online questionnaire designed to identify the most common sources of positive influence to their currently successful entrepreneurial leadership experience (reflected in Figure I.). There are six categories of influence tested: self-awareness; self-leadership; collaboration/social co-construction; business structure; and industry expertise. The participating voices recognise self-awareness as their highest form of positive influence (indicated below by the lowest mean score of 8.79) and student leadership experience as their lowest (indicated below by the highest mean score of 23.46). What seems significant about these voices is that they do not change in this response pattern from a small sample size of 50 to a larger sample size of 216 . Whilst the many voices from both male and female entrepreneurs from New Zealand and South Africa seem consistent, we are mindful that their views present more as a collective choral hum of agreement through a framework of enquiry, with certain assumptions, which could represent barriers to different perspectives (Patton, 20I5). We have asked them to speak with a limited vocabulary and improvisation is controlled. In the background of this study, Tom, Jordan, and Tiffany who are still voiceless, raise their heads with interest as we consider these findings. In moving to the next phase of the research the question lurks "what did we not ask in this survey?"

Figure I. Summary of the most common sources of positive influence to successful entrepreneurial leadership experience.

\begin{tabular}{|c|c|c|c|c|c|c|}
\hline 31st March 2021 & Self-Awareness & Self-Leadership & Social CC collaboration & Business Structure & Industry Expertise & Student Leadership \\
\hline Mean & 8.79 & 13.72 & 12.13 & 10.68 & 13.25 & 23.46 \\
\hline Standard Error & 0.17 & 0.30 & 0.26 & 0.24 & 0.28 & 0.45 \\
\hline Median & 8 & 13 & 12 & 10 & 13 & 24 \\
\hline Mode & 8 & 11 & 10 & 9 & 11 & 30 \\
\hline Standard Deviation & 2.45 & 4.38 & 3.86 & 3.47 & 4.06 & 6.61 \\
\hline Sample Variance & 5.99 & 19.19 & 14.94 & 12.02 & 16.50 & 43.69 \\
\hline Kurtosis & 1.50 & -0.11 & 0.71 & 8.72 & 0.49 & -0.74 \\
\hline Skewness & 0.94 & 0.55 & 0.83 & 1.80 & 0.60 & -0.20 \\
\hline Range & 14 & 21 & 20 & 29 & 21 & 28 \\
\hline Minimum & 5 & 5 & 5 & 5 & 5 & 7 \\
\hline Maximum & 19 & 26 & 25 & 34 & 26 & 35 \\
\hline Sum & 1898 & 2964.48 & 2621 & 2307 & 2860.95 & 5068.31 \\
\hline \multirow[t]{2}{*}{ Count } & 216 & 216 & 216 & 216 & 216 & 216 \\
\hline & 1 & 5 & 3 & 2 & 4 & 6 \\
\hline
\end{tabular}




\section{THE SOLO VOICES - DOCUMENTARY REFLECTIONS}

"A questionnaire is like a photograph. A qualitative study is like a documentary film" (Patton, 2015, p. 60).

Phase two of the research is qualitative and delivers the strongest, untenured voices to the research process through interviews with 20 currently successful entrepreneurial leaders. Each voice is powerful, unique, and certain of its own version of the truth. Constructivism, purposely addresses the concept of 'truth' and allows for multiple truths whilst calling to the credibility of the researcher interpretation through prolonged and persistent observation, triangulation, and negative case analysis (Miall et al., 2005, p. 145). The supervisory research team debates the experience of the practitioner as an entrepreneur, an entrepreneurial trainer and a student leadership trainer. Does this experience lend towards persistent observation or innate bias? We settle on a mix of both with the awareness of the value of ongoing self-reflection as the auto-ethnographic researcher in a unique space for experienced and insightful interpretation opportunities (Ellis et al., 20I0). Essentially the research question will direct what is included through the lens of what can be considered to be helpful in the earlier preparation of our future business leaders.

Through this question lens, the Interview participants are encouraged to explore their thinking and experiences with a set of questions both prepared and spontaneous. These questions are not related to the nature of their business but to the nature of their views of their entrepreneurial leadership journey. The practitioner's voice speaks quietly, probing to open spaces for thinking and reflection from hard-won experience as an interested observer with limited offered opinion. Some spaces are deemed comfortable by the participants and some not, but at times the silence also speaks. These voices are impactful not because they are loud but because they are free. They are free to explore their paths and they are free to construct their own realities as they wish. Strong patterns emerge as these spirited if previously isolated voices relate their stories, their experiences, their challenges, and their triumphs.

\section{UNACCOMPANIED - INTERVIEW RESULTS}

We now invite a selection of these voices to speak unaccompanied into this article. Each voice represents a successful entrepreneurial leader, captured in their raw form, to further explore our two outermost points of positive sources of influence to entrepreneurial leadership identified in the survey. Self-awareness being the highest and student leadership experience being the lowest.

"How important do you think self-awareness is to entrepreneurial leadership" is asked first, to further explore the personal feelings and experiences of the concept of self- awareness.

Voice \#4: Everything,... it's everything..

Voice \#I: I think it's huge. You know, no-one's perfect. So if you're aware of where your weaknesses lie, and you work on them, and sometimes environment will force you to work on things you don't want to do.

Voice \#2: Huge, that's critical. You've got to know where you are, first of all in terms of your thinking and then your emotional states.

Voice \#6: That's very important. Now, if you're not self-aware, and you're not self-aware enough to understand where you're going and how you're going about that, things can fall on a task very quickly.

Voice \#8: It all comes down to self-awareness, doesn't it ...

Voice \#9: Massive. I think it's one of the core principles that every entrepreneur needs is selfawareness. And to put a lot of time into it. 
Voice \# I0: Oh, god, yes. Absolutely. If you don't you die.

Voice \#II: 198\%. It's not the hard skills, it's the soft skills.

Whilst only in the early stages of analysis, it becomes obvious that these responses all reflect on three common themes. The first is that self-awareness is recognised as fundamentally important to their success. The second is that they have different interpretations of self-awareness and the third is that they felt theirs had been hardwon by experience. None of the interview participants related any experiences of having been taught about self-awareness during their formative educational years.

Voice \#18: It isn't important!

One voice does not resonate with the harmonious messages of the others. This is an unexpected response and we follow it to see where it leads. Upon further exploration, it appears that the cultural background of the participant treats the collective concept of leadership with more focus than an individual concept of leadership. Through their framing, it did not seem relevant and they did not seem to have the language for it. Further questions revealed that they did in fact have a high level of self-awareness. This striking difference in understanding of the relevance of the term indicates necessary attention to the manner in which we approach leadership training within different cultural backgrounds who chorus differently to a definition central to our enquiry. We remain mindful of the value of this voice to the pragmatic value of our research as it translates ultimately into a professional practice product.

Tom stands quietly in the shadows through the interview process but as they come to an end he is standing taller. His growing sense of self, whilst still silenced suggests that it is through these versions of himself, further down the track that he is finding his voice.

We then turn the focus of our enquiry to the area of student leadership as a positive source of influence, with the question

\section{"How did your experience of student leadership at high school help to prepare you for your entrepreneurial leadership role?"}

Voice \#3: Not at all. I think. I personally think that the education system in the world is broken. And I think that stuff that they never taught anybody in leadership they should teach in schools.

Voice \#4: Next question.......zero. So they're (the teachers) trying to teach you, you know, what you should do and all that. But truthfully, they've just, you know, they've just seen it in a picture somewhere or read it in a book.

Voice \#I: I've often seen by looking just at my own schooling career, a lot of the people that have been successful in my year, were not prefects were not head boys.

Voice \#2: So it didn't. Probably from a negative side.

Voice \#6: I learned everything about what not to do. Yeah, it was negative.

Voice \#7: Very badly. Next question?

Voice \#5: Made me tougher. Made me realise that you're not going to rely on anyone else. So it was I guess a reverse..... reverse influence if you like.

Voice \#9: I was head boy in my last year. But the, the sense of leadership when you're at high school, you know, head boy, head girl, or prefect, or whatever it is, to me now feels very fictitious and very, very staged. I didn't experience leadership at school. To me, I experienced a title and a badge. 
Voice \# 10: Not in a positive way. And yeah, they just had their views that, you know, fit in our ways, or, you know, you can beat it. I don't know how to change it, because the school system is going to take a very, very long time to change.

Tiffany and Jordan move forward now too as they listen carefully to these accounts which unwittingly echo their own thoughts, habitually buried in their journey of self-identity discovery so far. As before, they are happy for others to speak for them but they are grateful for the opening of a new dialogue.

In the early stages of our analysis, a common response theme develops quickly. The question is framed "How did your school experience help you?" which is intended to encourage a positive response as we are wary of leading any negative association. The immediate and pivotal swing from positive to negative of "it didn't" from the participants is decisive and abrupt. These responses suggest that the fundamental void identified between the two environments of leadership that our question seeks to illuminate has been experienced and navigated with difficulty by these participants.

Voice \# 19: So, you just were this ordinary person, I guess, you know, yes, worked hard and did your thing. But you didn't think that you would be that person, you know, top eight other high school. So I definitely think that almost led to me thinking I should you know, I have a little bit more to offer. And I think maybe that's what's then led me to, you know, the position that l'm in currently.

There is this one exception. One voice out of the twenty interview participants strikes a sharp and loud discord in the response pattern which to this time is harmonious. Responding to the familiarity of the term "top eight" and the location of the participating voice, a question is added which is more personal than any of the others "which school did you go to?" The same school is named that the practitioner attended as a student. Critical reflection clashes with objective observation in this moment of discourse as two versions of truth stand out clearly from what seems a similar foundation of experience. We ponder the differences. The intensity of harmonious volume from other sources of enquiry cannot sound this lone voice out though, and again we are reminded of the value of its efforts to also be heard, most critically within the mind of the auto-ethnographic researcher.

\section{MOVEMENT - INTERVENTION ONE}

With exceptions aside but under consideration at this point in the research, the united voices are sufficient to reach a crescendo of proportions suited to a professional practice intervention designed for positive change. Our question of "How do we better prepare our future entrepreneurial/enterprise leaders earlier in their education" now whispers back a suggested answer in the form of another question. What if we could lay a foundation of self-awareness early enough in their developmental years to prepare them better with an inner voice, to navigate how the concept of leadership currently structured, communicated and insisted upon by our traditional school structures influences their own self-identity and leadership identity formation? Whilst the research supervisory team idles momentarily on the practical enormity of tackling such a project within a three-year study, the voice of one of the panel assessors to the learning agreement rings out, "don't limit your expectations. A doctorate of professional practice is exactly the place to go big." And so, we do. COVID-19 has also taught us that an on-line option is needed to be practical, accessible and affordable, and from a professional practice perspective we initiate and progress the digital design by inviting in the experienced voices of e-learning development.

In the next few weeks, students from eight high schools in New Zealand and South Africa, who are currently in their first year of high school are planning to trial the 'Leadership Literacy for Life' online course. The sample schools were gained through the interest of teachers who had already joined this conversation, recognising that schools could play a greater role in the preparation of our future leaders. Jordan, Tom, and Tiffany agree that 
the voices of the students who participate in the trial might be untested and faltering, but their voices are a significant start. We will be listening carefully for the harmonies, the true notes, and the discords in what they are able to tell us.

\section{FINALE}

Through the choir of voices collected by means of this research path, we hope to call loudly and distinctly to facilitate a fresh flow of research, information, and learning resources to better prepare our future entrepreneurial/enterprise leaders in New Zealand, and South Africa.

Sandy Geyer is the founder of EnQPractice and works in the area of entrepreneurial leadership development and student leadership as a speaker and trainer in New Zealand and South Africa. She is the co-founder of Allcopy Publishers PTY Ltd, an educational publishing company, and Quickvest, a property investment company in Cape Town, South Africa. Based in Auckland, she is currently undergoing her Doctorate of Professional Practice at Capable NZ.

Email: sandy@enqpractice.com

(D) https://orcid.org/0000-0003-0/12-230।

Jan Hendrik Roodt is a transdisciplinary systems design engineer with business interests in New Zealand and Finland. He acts as postgraduate supervisor and assessor of masters and doctoral students in professional practice and applied innovation at the Otago Polytechnic and Waikato Institute of Technology in New Zealand. Based in Dunedin, he is a member of the Institute of Electrical and Electronics Engineers (Systems Council), the International Council on Systems Engineering, and Information Technology Professionals New Zealand.

(D) https://orcid.org/0000-000I-5250-8066

\section{REFERENCES}

Archard, N. (2012). Student leadership development in Australian and New Zealand secondary girls' schools: A staff perspective. International Journal of Leadership in Education, 15(I), 23-47. https://doi.org//0.1080//3603124.2011.605472

Bushe, B. (2019). The causes and impact of business failure among small to micro and medium enterprises in South Africa. Africa's Public Service Delivery and Performance Review, 7(I). https://doi.org/I0.4102/apsdpr.v7il.210

Caliendo, M., Fossen, F., \& Kritikos, A. (201 I). Personality Characteristics and the Decision to Become and Stay Self-Employed. IDEAS Working Paper Series from RePEc. http://search.proquest.com/docview/1698182369/?pq-origsite=primo

Chung-Wen, Y. (2008). The Relationships Among Leadership Styles, Entrepreneurial Orientation, and Business Performance. Managing Global Transitions; Koper, 6(3), 257-275.

Coffey, A., \& Lavery, S. (2018). Student leadership in the middle years: A matter of concern. Improving Schools, 21 (2), I87-200. https://doi.org/10.1177//365480217732223

Crowley, K., \& Head, B. W. (2017). The enduring challenge of 'wicked problems': Revisiting Rittel and Webber. Policy Sciences, 50(4), 539-547. https://doi.org//0.1007/s II077-017-9302-4

Davison, R., Martinsons, M. G., \& Kock, N. (2004). Principles of canonical action research. Information Systems Journal, 14(I), 65-86. https://doi.org/10.1111/j.1365-2575.2004.00162.x

Dewey, J (1997). Experience and education (Reprint Edition). Simon \& Schuster.

Ellis, C., Adams, T. E., \& Bochner, A. P. (2010). Autoethnography: An Overview. Forum Qualitative Sozialforschung / Forum: Qualitative Social Research, 12(I), Article I. https://doi.org/10.17169/fqs-12.1.1589

Gartner, W. (1985). A conceptual framework for describing the phenomenon of new venture creation. Academy of Management. The Academy of Management Review (Pre-1986), 10(000004), 696. 
Geyer, S. (2013). Path of the lion: Build your EnQ. Build your business. Allcopy Publishers.

Hine, G. (2014). Student Leadership Development: A Functional Framework. Journal of Catholic Education, 18(1), 79-110. https://doi.org/10.15365/joce.1801052014

livari, J., \& Venable, J. (2009). Action research and design science research—Seemingly similar but decisively dissimilar. $1642-1653$.

Johnson, A. M., Vernon, P. A., McCarthy, J. M., Molson, M., Harris, J. A., \& Jang, K. L. (1998). Nature vs nurture: Are leaders born or made? A behavior genetic investigation of leadership style. 8.

Kolb, C., \& Wagner, M. (2015). Crowding in or crowding out: The link between academic entrepreneurship and entrepreneurial traits. The Journal of Technology Transfer, 40(3), 387-408. https://doi.org/l 0. I007/s 10961-014-9346-y

Mansfield, M. (2019, March 28). STARTUP STATISTICS - The Numbers You Need to Know. Small Business Trends. https:// smallbiztrends.com/2019/03/startup-statistics-small-business.html

McNae, R. (20ll). Student Leadership in Secondary Schools: The influence of school context on young women's leadership perceptions. Leading and Managing, 17(2), 36-51.

Miall, C. E., Pawluch, D., \& Shaffir, W. (2005). Doing ethnography: Studying everyday life. Canadian Scholars' Press.

Moroz, P. W., \& Hindle, K. (2012). Entrepreneurship as a Process: Toward Harmonizing Multiple Perspectives. Entrepreneurship Theory and Practice, 36(4), 78I-8I8. https://doi.org/I0.1 III/j.1540-6520.201I.00452.x

Neck, H. M., \& Corbett, A. C. (2018). The Scholarship of Teaching and Learning Entrepreneurship. Entrepreneurship Education and Pedagogy, I(I), 8-4I. https://doi.org/I0.II77/25I5I274I7737286

Neck, H. M., \& Greene, P. G. (20II). Entrepreneurship Education: Known Worlds and New Frontiers. Journal of Small Business Management, 49(I), 55-70. https://doi.org/I0.1111/j.1540-627X.2010.00314.x

Nieuwenhuizen, C., Groenewald, D., Davids, J., Janse van Rensburg, L., \& Schachtebeck, C. (2016). Best practice in entrepreneurship education. Problems and Perspectives in Management, 14(3), 528-536. https://doi.org/l0.2151I/ ppm.14(3-2).2016.09

Patton, M. Q. (2015). Qualitative research \& evaluation methods: Integrating theory and practice (Fourth edition). SAGE Publications, Inc.

Rittel, H. W. J., \& Webber, M. M. (1973). Dilemmas in a general theory of planning. Policy Sciences, 4(2), I55-I69. https://doi. org/10.1007/BF01405730

TED. (2007, January 7). Do schools kill creativity? I Sir Ken Robinson [Video]. YouTube. https://www.youtube.com/ watch? $=$ iG9CE55wbtY 